\title{
Plasma rico en plaquetas. Una revisión bibliográfica
}

\author{
BECA T* \\ HERNÁNDEZ G* \\ MORANTE S** \\ BASCONES $\mathrm{A} * * *$
}

Beca T, Hernández G, Morante S, Bascones A. Plasma rico en plaquetas. Una revisón bibliográfica. Av Periodon Implantol. 2007; 19, 1: 39-52.

\section{RESUIMIEN}

Se presenta una revisión bibliográfica de la evolución en la literatura acerca del plasma rico en plaquetas (PRP). Tras una introducción se expone la composición del PRP, aludiendo fundamentalmente a los factores de crecimiento presentes en él para continuar con la secuencia de obtención y empleo quirúrgico del producto. Posteriormente se puede observar una revisión del proceso de regeneración a nivel histológico desde el momento de colocación hasta la sexta. En el apartado de discusión, se pueden observar los distintos estudios a favor y en contra de la utilización del PRP encontrados en la literatura, y a continuación se apuntan los posibles riesgos recientemente atribuibles al empleo del PRP para terminar con una breve revisión de estudios comparativos de diversos métodos de obtención y activación del PRP. Por último, se establecen una serie de conclusiones y se expone la bibliografía consultada.

\section{PALABRAS CLAVE}

Plasma rico en plaquetas, regeneración, PRP.

Fecha de recepción: Mayo 2006.

Aceptado para publicación: Julio 2006.

\section{INTRODUCCIÓN}

El tratamiento de las distintas patologías bucodentales muchas veces exige al profesional llevar a cabo terapéuticas de resección de mayor o menor complejidad lo que conlleva la pérdida de dientes y de soporte óseo. Como consecuencia de estas pérdidas existe una reabsorción progresiva del reborde alveolar que se traduce en una considerable perdida ósea vertical y horizontal, suponiendo dificultades añadidas para el tratamiento con implantes osteointegrados ya que el tejido óseo alveolar y la mucosa gingival sufren cambios morfológicos y funcionales causados por la etiopatogenia de cada situación.
Todas estas condiciones han llevado a la investigación de nuevas técnicas de regeneración ósea y a la utilización de diversos métodos de reconstrucción con injertos. A partir de lo expuesto se comprende la razón de una constante búsqueda de materiales capaces de sustituir el hueso perdido e intentando evitar intervenciones añadidas para la obtención de injertos, sobre todo, cuando son necesarias grandes cantidades como puede ser en las reconstrucciones óseas posteriores a un tratamiento radical oncológico, traumatismos o en los casos de elevaciones sinusales previos a la colocación de implantes.

Se han estudiado y aplicado numerosos sustitutos óseos en implantología oral, considerando sus venta-

\footnotetext{
* $\quad$ Experto en Clínica Periodontal. Alumno de Doctorado.

** Alumno del Master de Periodoncia UCM.

*** Catedrático de Periodoncia de la Universidad Complutense de Madrid.
} 
jas y aplicaciones específicas, en la búsqueda de un material bioactivo con capacidad de diferenciación osteoblástica que favorezca la regeneración. Se dice que el sustituto óseo ideal debe ser osteogénico, osteoinductivo y osteoconductivo:

- El término osteogénesis hace alusión a la formación y desarrollo de hueso en sentido genérico. Un material es osteogénico si se deriva o se compone de tejido involucrado en la formación de hueso.

- La osteoinducción es el proceso de estimulación de la osteogénesis. Para que un injerto sea osteoinductivo es preciso que sea capaz de formar hueso en áreas donde no se forma normalmente.

- Se entiende como osteoconducción a la capacidad de ciertos materiales de formar una matriz a través de la cual se puede depositar nuevo hueso. Los injertos osteoconductivos permiten la proliferación del tejido óseo desde las zonas anatómicas óseas preexistentes.

En este contexto se empezó a investigar y utilizar el plasma rico en plaquetas (PRP) con la intención de ir mas allá de la reparación de las heridas quirúrgicas y conseguir regeneración de los tejidos perdidos. Hablamos de reparación de un tejido cuando hay restauración de dicho tejido sin que este conserve su arquitectura original ni tampoco su función. Cuando dicho tejido no recupera su estado original, se produce una cicatrización. Por otra parte, se entiende por regeneración cuando la restauración de dicho tejido posee propiedades indistinguibles del tejido original. El problema con el tejido de cicatrización (reparación) es que no recupera todas las propiedades mecánicas ni la función fisiológica del tejido u órgano original que ha sido dañado, por lo que el interés en el PRP radica en regenerar, reconstruir la forma y restaurar la función.

Por tanto, la táctica terapéutica del PRP se fundamentaría en la modulación y aceleración de los procesos cicatriciales a través de los factores de crecimiento presentes en las plaquetas, iniciadores universales de casi todo proceso de regeneración (6).

\section{FACTORES DE CRECIMIENTO PRESENTES EN ELPRP}

Bioquímicamente, el PRP se compone de suero, leucocitos, plaquetas y factores de crecimiento, pero aunque la presencia conjunta de todos estos elementos favorece la acción del PRP, los elementos fundamentales son los factores de crecimiento, que ejercen la función de regeneración del lecho donante y que, en lí- neas generales, son el factor de crecimiento de origen plaquetario (PDGF), el factor de crecimiento de transformación-beta (TGF-beta), el factor de crecimiento fibroblástico (FGF), el factor de crecimiento similar a la insulina (IGF), el factor de crecimiento endotelial vascular (VEGF) y el factor de crecimiento epidérmico (EGF).

\section{PDGF}

- Promueve indirectamente la angiogénesis a través de los macrófagos, por un mecanismo de quimiotaxis.

- Activador de macrófagos.

- Mitógeno de células mesenquimales.

- Facilita la formación de colágeno tipo I.

\section{TGF-BETA}

- Quimiotaxis.

- Proliferación y diferenciación de las células mesenquimales.

- Síntesis de colágeno por los osteoblastos.

- Pro-angiogénesis.

- Inhibe la formación de osteoclastos

- Inhibe la proliferación de células epiteliales en presencia de otros factores.

\section{FGF}

- Proliferación y diferenciación de los osteoblastos.

- Inhiben los osteoclastos.

- Proliferación de fibroblastos e inducción de la secreción de fibronectina por estos.

- Pro-angiogénesis por acción quimiotáctica sobre células endoteliales.

\section{IGF}

- Proliferación y diferenciación de células mesenquimales y de revestimiento.

- Síntesis de osteocalcina, fosfatasa alcalina y colágeno I por los osteoblastos.

\section{VEGF}

- Quimiotaxis y proliferación de células endoteliales

- Hiperpermeabilidad de los vasos sanguíneos. 


\section{EGF}

- Mitógeno, proapoptótico, quimiotaxis y diferenciación de células epiteliales, renales, gliales y fibroblastos.

A nivel de acción frente a las distintas estirpes celulares, todos estos efectos podrían resumirse en la tabla 1 .

\section{OBTENCIÓNY FASES QUIRÚRGICAS}

\section{A. OBTENCIÓN}

El PRP es obtenido de la sangre autógena a través de un proceso que utiliza el principio de la separación celular por centrifugación diferencial, en el cual se extrae sangre del donante, se separan las distintas fases y se obtienen aquellas de mayor interés según el caso (7).

Los equipos utilizados para esta finalidad consisten en microcentrifugadoras como son:

- Separador celular de densidad gradiente Electromedics 500 (Medtronics).

- Compact Advanced Platelet Sequestration System (CAPSS).

- Equipo PRGF para la centrifugación y preparación del plasma (GAC Medicale-España).

- El sistema Curasan.

- El sistema PCCS.

El procedimiento puede ser realizado:

- En la consulta odontológica.

- En servicios hematológicos.

Independientemente del lugar donde se va a realizar, es importante para el éxito de este procedimiento que las plaquetas presenten calidad y cantidad favorables para la obtención de PRP. De esta forma, todo paciente que sea sometido a este procedimiento debe ser asistido por un hematólogo, que en período preoperatorio va a evaluar la función plaquetaria. Debido al turnover diario las muestras de plaquetas no serían válidas transcurridos unos días.

Últimamente es muy frecuente el empleo de microcentrifugadoras en la propia clínica, para cuyo uso se debe adiestrar al personal pertinente. La obtención del PRP debe ser cuidadosa, y el método muy reglado, ya que algunas veces ciertos parámetros de control se pierden por defectos infraestructurales, ya que el producto obtenido no puede ser analizado previamente a la inserción en el paciente, por lo que es fundamental la monitorización previa del paciente en estos casos. Si la obtención se realizara en un banco de sangre, existiría la posibilidad de, mientras se prepara el PRP, realizar el recuento de plaquetas para certificar y confirmar que estas se encuentran numéricamente dentro de los valores esperados, iguales o aproximados a los valores obtenidos en las analíticas preoperatorias $(7,14,15)$.

La secuencia del proceso es básicamente la siguiente:

- Punción venosa.

- Extracción de la sangre.

- Separación celular.

\section{PUNCIÓN VENOSA}

Se realiza la extracción de sangre al paciente de la región antecubital, unos minutos antes de comenzar la cirugía. La cantidad dependerá del defecto a tratar, de la forma de presentación (solo PRP, en forma de gel de plaquetas, mezclado con un material de injerto autó-

\begin{tabular}{|lccccc|}
\hline \multicolumn{7}{c}{ TABLA 1 } \\
\hline & $\begin{array}{c}\text { Proliferación } \\
\text { pre/osteoblastos }\end{array}$ & $\begin{array}{c}\text { Proliferación } \\
\text { fibroblastos }\end{array}$ & Quimiotaxis & $\begin{array}{c}\text { Síntesis de matriz } \\
\text { extracelular }\end{array}$ & Vascularización \\
\hline PDGF & ++ & ++ & + & + & $*$ \\
TGFß & $+/-$ & +- & + & ++ & $*$ \\
EGF & + & ++ & + & + & - \\
IGF & ++ & + & - & - & ++ \\
VEGF & + & & + & + & + \\
\hline
\end{tabular}

++ Gran Aumento; + Aumenta; - Sin efecto; * Efecto indirecto (4). 
logo/heterólogo, etc.), o bien del lugar donde se realice (clínica dental o banco de sangre).

\section{OBTENCIÓN DE LA SANGRE}

En el banco de sangre, se efectúa un acceso venoso a través de una cánula que permite la retirada de la sangre venosa y esta se almacena en bolsas rotuladas con anticoagulantes listas para el proceso de centrifugación (7). El volumen medio de una bolsa de sangre es de 440 a 460 mililitros, y estas serán almacenadas en un lugar apropiado hasta el momento de la centrifugación. De forma ambulatoria, cabe pensar en que la extracción de tal cantidad de sangre, aparte de la necesidad de un personal entrenado, puede parecer un poco traumática según qué pacientes.

\section{SEPARACIÓN CELULAR}

La fase de centrifugación debe ser realizada por un profesional para permitir la obtención de la máxima concentración de las plaquetas por unidad de volumen, sin la rotura de las mismas. Se centrifuga el plasma con un equipo digital que nos va a garantizar que los parámetros de tiempos y velocidad son los adecuados. La velocidad de rotación depende del protocolo de obtención (un solo centrifugado o doble centrifugado) y del volumen recogido. Cualquier alteración en la estandarización del centrifugado puede producir daños estructurales en las células sanguíneas.

La separación de los elementos de la sangre después del proceso de centrifugación se da en función de la densidad, de mayor a menor. $(6,7,14)$ Existen dos protocolos:

- Única centrifugación.

- Doble centrifugación (8).

En este último, la primera centrifugación se puede realizar a una velocidad de $280 \mathrm{~g}$ (1.400 rpm) durante 7 minutos (14), o bien a $160 \mathrm{~g}$ (1.200 rpm) durante 10 minutos, según otros autores $(16,17,18)$. Con esta primera centrifugación se consigue separar la sangre completa en una franja roja inferior de hematíes y otra amarillenta superior de plasma. Este plasma contiene una concentración relativamente baja de plaquetas (es lo que se denomina plasma bajo o pobre en plaquetas, PPP). Entre una franja y la otra se encuentra la mayor concentración de plaquetas, y recibe el nombre de franja leucocitaria, y en la franja inferior roja se encuentran los componentes celulares sanguíneos. Se extrae el plasma amarillento (PPP) del tubo de sangre con una jeringuilla y posteriormente se introduce en un nuevo tubo, se coloca el tapón del tubo de ensayo y se realiza la segunda centrifugación.

El objetivo de la segunda centrifugación es separar y concentrar todavía mas las plaquetas obteniendo como producto final el plasma rico en plaquetas. Esta segunda centrifugación se hará a una velocidad de $400 \mathrm{~g}$ (2000 rpm) (6). Con este último proceso los tubos presentan una franja superior de suero sobrenadante de color amarillo claro, que contiene fibrinógeno y una concentración muy baja de plaquetas, y una franja inferior generalmente de color rojizo formada por PRP muy concentrado. Posteriormente se pipetea el suero sobrenadante y se queda un remanente de PRP de 0,5 $\mathrm{mm}$ aproximadamente en cada tubo, dependiendo de la cantidad inicial recogida. La concentración normal de las plaquetas en el hematocrito es de $33-40 \%$ de plaquetas, pero tras el proceso de doble centrifugado se puede obtener una concentración de plaquetas de $330 \%$ aproximadamente.

\section{B. FASE QUIRÚRGICA}

Una vez obtenido el plasma rico en plaquetas, este ya puede aplicarse al lecho mezclado con un material de injerto o bien utilizarse sin mezclar, y se puede aplicar en el lecho activándolo o no previamente. El PRP puede activarse solo (tarda demasiado) o mediante compuestos cálcicos, aunque para ello hay que esperar por lo menos 8 o 10 minutos o más, con resultados variables. Aunque el uso de trombina bovina PRP es bastante seguro, en algunos países se prefiere evitar su uso por el riesgo de transmisión de enfermedades. También se puede optar por activar el PRP con 1 $\mathrm{ml}$ de sangre autóloga y algo de hueso esponjoso autógeno, ya que ambos contienen trombina. (7) Los últimos estudios experimentan con el empleo de un activador sintético, el TRAP, del que hablaremos más adelante.

La fase de fibrina sobrante en el tubo de ensayo puede emplearse, aplicada sobre una superficie lisa con cierta temperatura, para la obtención, una vez coagulada la fibrina de una auténtica membrana reabsorbible que se puede aposicionar a modo de barrera entre el material injertado y los tejidos blandos, pero su estabilidad es variable y se reabsorbe muy rápidamente. 


\section{PROCESO DE REGENERACIÓN}

La comprensión de las fases de regeneración tisular en el modelo cicatricial es esencial para entender los mecanismos de reparación ósea y de los beneficios que pueda tener el PRP en este proceso $(9,19,20)$. Aunque no se conoce de forma concreta la cascada de remodelación ósea, se sabe que está muy relacionada con el control ejercido por parte de numerosos factores de crecimiento, como son el PDGF, TGF, FGF, IGF-I y II... Hoy sabemos acerca de la existencia de células madre "adultas" precursoras de distintos tipos celulares locales en todos los tejidos del organismo, que no deben confundirse con las células madre embrionarias pluripotenciales. Según las últimas investigaciones en bioingeniería, parece ser que, si bien los factores de crecimiento descritos pudieran promover la diferenciación y/o proliferación de los tipos celulares preosteoblastos y de su estirpe (los osteoblastos), dichos factores no tendrían ningún efecto sobre la diferenciación celular de estas células madre adultas a preosteoblastos (fase regulada por las famosas BMPs). En consecuencia, los factores de crecimiento actuarían únicamente sobre esa segunda parte de la diferenciación celular.

El mecanismo fundamental de liberación de factores de crecimiento por los concentrados plaquetarios es de difusión, y se basa en los gradientes de concentración de los distintos factores en un momento específico de la cicatrización. La concentración temporal y la distribución espacial de los factores dentro del lugar de injerto varían en función de la infiltración del fluido durante la respuesta reparativa inicial, por lo que es fundamental tener en cuenta estos dos factores a la hora de verificar la eficacia del PRP en la regeneración tisular, es decir, la activación y presencia puntual en el momento y concentración exactos es un punto crítico en el inicio de la cascada de la regeneración $(19,20)$.

\section{A. MOIMENTO DE COLOCACIÓN}

En un primer momento, se establece en el lecho un coágulo de fibrina debido a la agregación plaquetaria, con lo que se favorece la aparición de un entorno de hipoxia respecto al lecho receptor bien oxigenado, disminuyendo su pH hasta 4 ó 6 respecto al lecho receptor (cuyo $\mathrm{pH}$ es de 7). Por tanto, desde el principio todos estos estímulos provocan el inicio de la revascularización de la zona, la migración de células pluripotenciales, de células osteocomponentes y la mitogénesis de células osteoprogenitoras y fibroblastos. En este ambiente, la cicatrización ósea comienza por la liberación de factores de crecimiento en el injerto, inmediatamente después de darse la ruptura de los gránulos plaquetarios. Los factores liberados son, principalmente, PDGF, TGF- $ß$ e IGF.

\section{B. PRIMERA SEMANA}

La acción iniciada por los factores de crecimiento liberados por las plaquetas será continuada a partir del tercer o cuarto día por los factores de crecimiento liberados por los macrófagos, ya que la hipoxia en la que se encuentra el coagulo de fibrina, en contraposición con el lecho receptor que se encuentra más oxigenado, crea un gradiente de oxígeno que induce la quimiotaxis de los macrófagos, que continúan liberando factores de crecimiento (PDGF, TGF-ß, IGF-I, FGF).

Durante este tiempo continúa de forma activa la revascularización del coágulo de fibrina debido al proceso de angiogénesis. El PDGF estimula la mitogénesis de las células desde el canal medular transferida junto con el injerto, y se inicia la angiogénesis del complejo capilar en el interior del injerto inducida por la mitosis de las células endoteliales $(2,7,15)$.

El TGF- $ß$ estimula la mitogénesis de preosteoblastos y osteoblastos aumentando el numero de estas células a la vez que promueve su diferenciación hacia osteoblastos maduros. La continua secreción de TGF- $\beta$ favorece la formación de matriz ósea y colágena formada por fibroblastos y osteoblastos respectivamente.

El IGF, a su vez, actúa sobre los osteoblastos endoóseos, limitando así las trabéculas del hueso esponjoso injertado (7).

Entre el quinto y el séptimo día, a través del mecanismo de quimiotaxis, el PDGF (juntamente con el gradiente de oxígeno) atrae los macrófagos hacia el área injertada. A partir de aquí, los procesos regenerativos serán estimulados por los factores de crecimiento derivados de los macrófagos. La respuesta autocrina de autoestimulación continúa gracias a las células del canal medular que segregan constantemente TGF- $\beta$ y IGF.

\section{SEGUNDA Y TERCERA SEIMANA}

En esta fase, la actuación directa de los factores de crecimiento permite el mantenimiento de los procesos cicatriciales, principalmente la mitogénesis de las cé- 
lulas del canal medular y la angiogénesis capilar, con lo que, alrededor de los días 14 y 17 , se puede ver la completa permeabilidad capilar del injerto.

Estos capilares responden al gradiente de oxígeno con lo que, posteriormente a su difusión en el injerto, se establece un mecanismo inhibidor para prevenir una superangiogénesis. $(7,15)$

Se origina entonces la coalescencia de las islas osteoides individuales a la superficie osteoide, sobreviniendo el proceso de consolidación clínica del injerto (15). Se relaciona este momento con la fase I de la regeneración ósea, es decir, la aparición de tejido óseo trabeculado desorganizado, sin sistemas harvesianos.

\section{CUARTA A SEXTA SEMANA}

En esta etapa, el injerto está revascularizado y la regeneración ósea es casi completa, desaparecen los macrófagos y se inicia el proceso de reabsorción y reposición. Se produce en este punto la liberación de BMP y IGF, proteínas ácido-insolubles que actúan en las células adyacentes del canal medular y preosteoblastos induciendo la proliferación y diferenciación de éstas en osteoblastos funcionales, que secretarán matriz ósea.

Este proceso definirá una arquitectura ósea madura con sistema harvesiano característico del hueso de fase II, autosustentado. De esta forma, a través de un ciclo normal de reabsorción-remodelación y progresión del injerto de un transplante celular para un hueso maduro y funciona $(7,9,19,20)$.

\section{DISCUSIÓN}

Desde los comienzos de la investigación con PRP se han publicado numerosos trabajos de investigación que arrojan óptimos resultados en la aplicación del mismo utilizado sólo o mezclado con material de injerto autólogo o heterólogo. Los primeros estudios se mostraron bastante optimistas, pero, tras un período extenso de polémica, parece que en la actualidad se pone en entredicho la eficacia de este procedimiento. Si bien está clara la acción regenerativa tisular del producto in vitro, hay resultados clínicos que se muestran de acuerdo y otros que no se corresponden con lo observado en dichos estudios.

En lo que sí parecen concordar la mayoría de los estudios es en dos puntos: la mejora visible de la cicatriza- ción de los tejidos blandos y una mayor cohesividad en los injertos particulados, que facilita su manipulación.

\section{A. A FAVOR}

Marx y cols. (10) realizaron un estudio en 88 pacientes en los que se efectuaron reconstrucciones con injertos medulares celulares y esponjosos en defectos mandibulares de continuidad de $5 \mathrm{~cm}$ o más; en 44 reconstrucciones utilizaban injertos a los que añadían PRP, y los otros 44 casos sirvieron como grupo control. Como resultados obtuvieron:

- Los injertos en el grupo test presentaban un índice de maduración 1,62 a 2,16 veces superior que en el grupo control.

- El estudio histomorfométrico demostró además una mayor densidad ósea en el grupo test $(74 \% \pm 11 \%)$ que en el control $(55 \% \pm 8 \%)$.

Anitua y cols. (14) en una muestra de 20 pacientes, emplearon PRP en el tratamiento de defectos óseos postextracción con el objetivo del emplazamiento de futuros implantes, un grupo test con tratamiento alveolar con PRP y un grupo control, observando en el grupo test una mayor anchura ósea bucolingual y bucopalatina, una mayor densidad ósea y una cobertura tisular mas amplia con respecto a los no tratados con PRP. Es preciso destacar la parcialidad del estudio, si tenemos en cuenta la autoría.

Oyama y cols. (24) realizaron injertos de hueso alveolar con hueso autólogo de cresta ilíaca, incorporando PRP en 23 pacientes con labio leporino y fisura palatina, y concluyeron que el PRP es una método seguro y sencillo de extraer y que favorece la osteogénesis en los injertos de hueso alveolar en pacientes fisurados, pero el estudio presenta poca relevancia porque no presenta grupo control.

En el campo de Periodoncia, en un ensayo clínico realizado por Howell y cols. (25) para evaluar la aplicación PDGF-BB y IGF-I recombinante humano en 38 pacientes con enfermedad periodontal moderada 0 severa sugirieron tras diferentes mediciones óseas de control, que la aplicación local de PDGF-BB y IGF-I recombinante humano en lesiones periodontales mejora significativamente la regeneración ósea en la dosis adecuada, sobre todo en el caso del IGF. Es importante tener en cuenta que en el estudio no se estudia la aplicación del PRP tal y como lo conocemos sino que se trata de la aplicación de factores de crecimiento por 
separado y obtenidos por técnica recombinante, con lo que a efectos del PRP no tiene mucha relevancia.

Al tener en cuenta la posibilidad de asociarlo a injertos de hueso tanto autólogo como heterólogo, la literatura arroja datos bastante optimistas, aunque se necesita una mayor investigación, como concluyen la mayoría de los estudios. Kassolis y cols. (31) publicaron un estudio en el que llevaron a cabo un aumento del reborde alveolar y elevaciones sinusales utilizando PRP y hueso liofilizado aloplástico en 15 pacientes. Tras realizar biopsias en las zonas de implantación de los injertos, se llegó a la conclusión de que la utilización de hueso liofilizado junto al PRP en elevaciones sinusales y en aumentos de reborde alveolar es una alternativa terapéutica viable si se quiere utilizar como futuro emplazamiento de implantes; pero señala que se requieren más estudios para determinar si el PRP aumenta la regeneración y maduración ósea cuando se emplea junto a hueso liofilizado.

Un trabajo publicado por Arlene Rodríguez et al. (31) en el que se realizaron un total de 24 elevaciones de seno con hueso bovino desproteinizado y plasma rico en plaquetas, con inserción inmediata de implantes endoóseos, en 15 pacientes con menos de $5 \mathrm{~mm}$ de hueso residual en el maxilar posterior, observaron que la densidad de hueso formado en tres de los pacientes era similar a la del hueso propio, aunque hay que puntualizar que al haber analizado solo 3 de los 15 pacientes, el estudio no es muy concluyente.

En un trabajo publicado por Freymiller y cols. (32) en el que se hace una revisión de toda la literatura sobre el PRP que hay hasta el momento, analizando todas las posibles combinaciones de PRP (con hueso autólogo, con hueso mineral anorgánico y con hueso mineral orgánico e incluso solo) concluye que, la literatura en este campo esta en un período prematuro, y conflictivo y todavía hay áreas desconocidas en las que se deberá seguir investigando al respecto.

\section{B. EN CONTRA}

Aunque los resultados de los estudios en los que se han utilizado hueso autólogo para combinar el PRP parecen muy prometedores, otros indican que el empleo de PRP puede no ser tan efectivo, y arrojan datos que hacen pensar en la justificación de su utilización. Estas discrepancias en los distintos estudios puede explicarse por la posibilidad de aparición de grandes diferencias en la concentración de los factores de cre- cimiento según el método de obtención del producto empleado. Desde un principio, siguiendo las líneas de la investigación inicial, la presencia de factores de crecimiento en el PRP llevó a algunos profesionales a pensar que, a mayor concentración de dichos factores, más eficaz sería la regeneración, y se promovió el empleo de sistemas que obtenían una mayor concentración de los factores, sistemas que fueron homologados y que siguieron empleándose sin reflexionar en la concentración obtenida del producto final.

Lejos de conseguir el efecto deseado, in vitro se observa completamente lo contrario cuando la concentración de factores sobrepasa un cierto nivel. Así, en la literatura existe una fuerte polémica muy actual, polémica que en muchos casos viene servida por una deficiente descripción de materiales y métodos en algunos de los artículos revisados, pues en bastantes casos no se pormenoriza la sistemática de obtención del plasma, que puede ser incorrecta

Choi et al vieron, in vitro, como concentraciones progresivas mermaban la capacidad regenerativa de los autoinjertos. Parece ser que, en concentraciones progresivas de un 1 a un 5\%, el efecto del PRP radica en un incremento de la viabilidad y proliferación celular, cuando, en porcentajes superiores, el efecto se invierte y llega a inhibir el potencial regenerativo del injerto autólogo. Similares resultados se han visto en relación al PPP, de forma incluso que la respuesta es más citotóxica que ante el PRP. Parece ser que sólo en concentraciones de hasta un 5\% el PRP tendría su valor como inductor de la regeneración tisular, con lo que sería necesario estandarizar el procedimiento de sustracción del PRP con el fin de establecer un mecanismo seguro de regeneración tisular (34).

Butterfield y cols. (25) en un estudio en el que utilizaron PRP e injerto de hueso autógeno para elevaciones sinusales en 12 conejos vieron que no había incremento significativo en la ritmo de regeneración ósea, en su histología o en la densidad. Los 12 conejos fueron divididos en 3 grupos según el momento que fueron sacrificados (a la $2^{\mathrm{a}}$ semana, a la $4^{\mathrm{a}}$ semana y a la $8^{\mathrm{a}}$ semana). En todos ellos se aplicaron injertos de cresta ilíaca para realizar elevaciones sinusales bilaterales que se combinaron con PRP obtenido a partir de $21 \mathrm{cc}$ de sangre antóloga de los conejos. El seno maxilar izquierdo de cada conejo recibió el injerto sin combinar con PRP (control) y el derecho incluyó el PRP. Posteriormente los animales fueron sacrificados en grupos a la $2^{\mathrm{a}}$ semana, a la $4^{\mathrm{a}}$ semana y a la $8^{\mathrm{a}}$ semana, y fueron estudiados utilizando tomografías computarizadas 
periféricas cuantitativas, análisis histomorfométricos estáticos y dinámicos. Los resultados no mostraron diferencias estadísticamente significativas entre los casos y los controles, e incluso se observaron resultados más deficientes en los controles.

Arpornmaeklong et al. han estudiado in vitro, por otro lado, la aparente relación que existía entre la presencia del PRP y la regulación ósea efectuada por la fosfatasa alcalina, viendo como el PRP inhibiría la acción de la fosfatasa alcalina de forma dosis-dependiente: a mayor concentración del PRP, se inhibiría pues la diferenciación osteoblástica (caracterizada por un aumento de la fosfatasa alcalina y la mineralización) y aumentaría la proliferación de células preosteoblásticas, pero a bajas concentraciones no se ve un marcado efecto en la proliferación o diferenciación celular, con lo que el PRP tendría un comportamiento bimodal en función de la concentración. Así, mientras se observan altos niveles de actividad fosfatasa alcalina en cultivos con BMP-2, el PRP presentaría una acción inhibidora (en líneas generales) de la diferenciación osteogénica (37).

Otro artículos refieren esta falta de eficacia en asociación con injertos óseos: Mark y cols. (13) en un artículo publicado sobre qué es PRP y que no es PRP pone en tela de juicio que el PRP pueda estimular la regeneración ósea cuando este se combina con sustitutos óseos o materiales no celulares ya que el papel fundamental del PRP es mitogénico, es decir, estimular las células involucradas en la reparación de las heridas.

Froum y cols. concluyen, en un estudio realizado en tres pacientes en los que se realizaron 3 injertos sinusales con hueso bovino y PRP, que, tras un estudio histomorfométrico, la adición de PRP en los injertos no indujo ninguna diferencia significativa en la producción de hueso vital o en contacto óseo interfacial con los implantes estudiados, si bien el tamaño muestral es muy reducido y la falta de resultados puede deberse a una deficiente preparación del producto (26).

Para Shanaman y cols. (27) en un artículo publicado sobre un estudio realizado en tres pacientes en los que se efectuó un aumento de cresta alveolar combinando ROG y PRP; concluyeron que la adición de PRP no mejoraba significativamente la calidad de hueso neoformado si se comparaba con los que no se añadieron PRP.

Aghaloo y cols. (29) en un estudio piloto, en el que se utilizaron 15 conejos, en los que realizó cuatro orifi- cios de $8 \mathrm{~mm}$ de diámetro en el cráneo de cada conejo, dos se utilizaron como control y en los otros dos se añadió PRP. Los orificios fueron evaluados con radiografía digital de sustracción, análisis histológicos e histomorfométricos. No encontraron mejoras significativas en la regeneración ósea de los orificios tratados con PRP en comparación con los orificios controles.

\section{POSIBLES RIESGOS}

Los autores que han empleado clínicamente el PRP aseguran que no existen riesgos de infección o transmisión de enfermedades y niegan la existencia de algún tipo de efecto indeseable, y no existe ningún caso en la literatura que muestre resultados de este tipo. Sin embargo, se ha relacionado la sobreexpresión de factores de crecimiento y sus receptores con tejidos tumorales y displásicos, lo cual hace pensar en dos posibles peligros: la carcinogénesis y la posibilidad de favorecer la metástasis.

\section{A. CARCINOGÉNESIS}

Los factores de crecimiento son polipéptidos contenidos en diferentes tipos celulares y en la matriz extracelular, que juegan un papel fundamental en la estimulación y regulación de la curación de heridas en diferentes tejidos del organismo, y parecen regular diversos procesos celulares, como son la mitogénesis, quimiotaxis, diferenciación y el metabolismo celular.

Son innegables los buenos resultados de los tratamientos con concentrados de PRP en algunos casos, pero la evidencia científica muestra también de forma experimental que los factores de crecimiento encontrados en las plaquetas, PGFs, aparecen sobreexpresados en los tejidos tumorales. Así, en células tumorales se han observado unos 400.000 receptores normales de EGFR (Epidermal Growth Factor Receptor), en contraposición a fibroblastos normales que pueden presentar de 5.000 a 10.000. Este incremento se debe a alteraciones de genes codificadores de los receptores y no como consecuencia de la sobreproducción de GFs.

En un tejido normal el incremento de receptores sería moderado y transitorio, pero en determinadas ocasiones, la activación del receptor del EGFR podría inducir en ciertas células tumorales una detención de la proliferación celular y la inducción de apoptosis. En las células tumorales la presencia de un número excesivamente alto de copias de EGFR normal en la célula 
provocaría un aumento de la sensibilidad a sus ligandos que, incluso a concentraciones muy bajas, serían capaces de estimular las células e inducir proliferación celular.

Las dianas donde actúen las vías de los GFs estarían en continuo trabajo y, cuando esas dianas estuvieran saturadas, posiblemente las señales dadas por receptores adicionales serían ignoradas por falta de dianas disponibles. Cuando la señal de los GFs llega al núcleo, se activarían una serie de factores que facilitan la transcripción de diferentes genes implicados en el ciclo celular o en la diferenciación fenotípica de la célula. Los protooncogenes c-jun y c-fos, por ejemplo, son inducidos rápida y transitoriamente tras el tratamiento con GFs, y son los genes de estas dos familias los que controlan la respuesta proliferativa de un modo primario, activando (o inhibiendo) en cascada, genes cuyos productos ponen en marcha o detienen el ciclo celular.

Con estos datos se podría concluir la potencial carcinogénesis del PRP y, sin embargo, tras la extensa experiencia científica, no existe ningún caso descrito de lo anteriormente citado. Los concentrados terapéuticos de GFs como el PRP podrían actuar, pues, más que como iniciadores, como promotores en la carcinogénesis, pero este fenómeno necesitaría de dosis mayores y más continuadas en el tiempo que las que se aplican en la terapéutica convencional. Se debe tener en cuenta que los GFs extracelulares se degradan a los 710 días (8).

\section{B. METÁSTÁSIS}

Otro fenómeno a valorar sería la capacidad que pudieran tener las plaquetas para facilitar el proceso de metástasis de las células tumorales. Se sabe que las plaquetas recubren las células tumorales, facilitando su supervivencia y adhesión a las paredes vasculares, y por otro lado favorecen su permeabilidad vascular, lo que permite la penetración tumoral en el tejido perivascular, mediado principalmente por el VEGF (Vascular Epidermal Growth Factor). Parece además que las células tumorales facilitan la agregación plaquetaria liberando el VEGF de las plaquetas que necesitan para su invasión tisular.

Este fenómeno es necesario tenerlo en cuenta en el caso de que se aplicara el PRP en las vecindades de un tumor con capacidad metastatizante, pero en la mayoría de los casos, no nos vamos a encontrar con esta incidencia, sobre todo si hacemos un correcto diagnóstico de este tipo de lesiones.

\section{TRANSIMISIÓN DE PATÓGENOS}

Por último, cabe plantearse la transmisión de patógenos, cuyo origen podría establecerse en dos casos:

- Contaminación del producto durante o después de su obtención.

- Empleo de trombina bovina para la activación del mismo, con el riesgo actual de transmisión de priones.

Estos últimos, ante el abandono actual del empleo de la trombina bovina y la utilización de sistemas semicerrados con manipulaciones meticulosas no parecen tener mayor relevancia.

\section{IMEJORAS}

Transcurridos unos años en el empleo e investigación del PRP cabe plantearse mejoras en el sistema con el fin de obtener un producto final de mayor calidad o facilitar el manejo del mismo.

Para la obtención del PRP existen diversos métodos y técnicas ya descritas anteriormente, pero diversos autores como Weibrich y cols (39) han querido comparar su eficacia con de nuevos métodos. De este modo se realizó una comparación entre un sistema ya establecido como es el PCCS (platelet concentrate collection system) y el nuevo sistema de plasma rico en factores de crecimiento PRGF (plasma-rich-ingrowth-factors kit), aunque no se dieron diferencias significativas, aunque se debe tener en cuenta que, en contraste con el PRGF kit, el sistema PCCS es un sistema semicerrado, lo que conlleva a un disminución importante del riesgo por contaminación bacteriana. Se sabe por algunos métodos de producción que los niveles de factores de crecimiento en el PRP pueden variar tremendamente dependiendo de la concentración de plaquetas y leucocitos, por eso se concluyó eligiendo al sistema PCCS como el más eficaz, puesto que era el que más concentración presentó.

También comparando con el sistema PCCS, Weibrich y cols. (40) sometieron a prueba el sistema Curasan, que, siendo también un sistema de dos centrifugados, presentaba modificaciones en el número de revoluciones por minuto. En ambos se obtuvieron diferencias significativas entre las concentraciones de plaquetas y leucocitos, siendo la primera mayor en el PCCS y la 
segunda en el sistema Curasan, y se llegó a idéntica conclusión que en el estudio de Weibrich (39) para los niveles de factores de crecimiento.

Por otro lado, los métodos habituales de obtención del plasma se basan en el empleo de trombina bovina para conseguir una activación plaquetaria, aunque se han visto riesgos de episodios de coagulopatías por la presencia conjunta en estos preparados de factores V y IX y no sólo eso, sino también por la posibilidad de transmisión de ciertas enfermedades como la encefalopatía espongiforme, por lo que se han propuesto otros activadores como el TRAP, que están libres de factores contaminantes, con lo que se reducen riesgos. Este péptido es una sustancia artificial que promueve la formación del coágulo y la liberación de los factores de crecimiento contenidos en el PRP. De hecho, según un estudio llevado a cabo por Landesberg et al, se produce con este factor una mayor liberación de PDGF que en el caso de la trombina y, no sólo eso, cabe pensar en que el TRAP actúa promoviendo la liberación de los factores justo en el momento en que son necesarios, utilizándose, pues, en su mejor momento, y no permaneciendo libres para su posible degradación sin que hayan podido ejercer su función (38).

\section{CONCLUSIONES}

El Plasma Rico en Plaquetas es un producto autólogo, atóxico y no inmunorreactivo que se obtiene de la sangre. Se piensa que los factores de crecimiento contenidos en las plaquetas van a inducir la formación de hueso al aumentar su concentración en el lugar de aplicación confiriendo una habilidad plural al PRP para acelerar fenómenos regenerativos basándose en el alto potencial mitógeno del producto.

La aplicación del PRP en el campo de la Odontología, y ello es por tanto un punto negativo a tener en cuenta, se ha basado desde el principio en resultados clínicos por aplicación directa en pacientes, por lo que su empleo se ha venido realizando sin suficiente investigación. Hubiera sido necesaria mucha más información al respecto antes de su aplicación clínica.

Una importante distinción que merece la pena hacer es la ya comentada acerca del papel real de los factores de crecimiento sobre los preosteoblastos y osteoblastos, promoviendo su proliferación y diferenciación, que no sobre las células madre "adultas" presentes en el tejido, y cuya diferenciación da lugar a distintas estirpes celulares (fibroblastos, células epiteliales, oste- oblastos...). El PRP, como hemos visto, actuaría únicamente sobre células ya diferenciadas (preosteoblastos y osteoblastos), pero no sobre dichas células madre, sobre las que se ha demostrado recientemente una gran influencia reguladora por parte de las proteínas morfogenéticas del hueso (BMPs). Por ello cabe pensar en que los polémicos resultados en cuanto a la inducción en la osteogénesis pueden ser debidos a esta parcial acción.

Parece ser que la integración de los injertos de biomateriales no se ven favorecidos de forma estadísticamente significativa cuando se aplican asociados al PRP. Incluso algunos muestran un ligero detrimento en la integración del mismo en el lecho óseo, pero en lo que sí se muestran de acuerdo todos los estudios es en que el PRP facilita realmente el transporte de los biomateriales particulados al lecho.

Dado su alto potencial mitógeno, actúa de forma excelente en la cicatrización de los tejidos blandos, mejorando sensiblemente el postoperatorio del paciente, pero no se puede apoyar su empleo en clínica únicamente con este fin.

Es cierto que existen empíricamente ciertos riesgos como la carcinogénesis, la capacidad de metástasis y la transmisión de patógenos pero:

- No existe ningún caso descrito.

- El empleo del PRP según un método estandarizado no debe ni puede entrañar peligros de este tipo.

- Los concentrados terapéuticos de GFs como el PRP podrían actuar como promotores, no como iniciadores en la carcinogénesis, pero este fenómeno necesitaría de dosis mayores y más continuadas en el tiempo que las que se aplican en la terapéutica convencional.

En el apartado de mejoras, hemos observado las siguientes conclusiones:

- Parece que el sistema PCCS es óptimo, en comparación con otros sistemas, si bien hay que tener en cuenta que cualquier sistema semicerrado que presente una temperatura y revoluciones por minuto cercanas a los valores estándar puede presentar idénticos resultados sin necesidad de adquirir costosos equipos.

- El empleo del TRAP podría favorecer una óptima liberación espacial (en cuanto a concentración) y temporal justo en el momento en que los factores son necesarios, por lo que pudiera ser un complemento ideal para que el PRP ejerza su función, pero esta hipótesis no puede ser tenida en cuenta sin una mayor investigación al respecto. 
Desde un momento inicial, en Odontología su empleo ha ido decayendo por los resultados de algunos estudios que no ven mejoras en la regeneración de los tejidos. In vitro sí se ven, en líneas generales, resultados a nivel óseo (algunos estudios no) pero in vivo, los resultados varían mucho y existe mucha polémica. Esto podría deberse a una serie de factores que no es tenida en cuenta por la mayoría de los artículos:

- ¿Cuál es el método de obtención más idóneo para la obtención del producto? En principio no existe un consenso a este respecto sino que cada estudio emplea un sistema u otro sin plantearse el efecto en el producto final. Deberían realizarse estudios comparativos conjuntos de los distintos sistemas empleados y valorar los productos finales con el fin de establecer qué sistemas presentan finalmente un producto adecuado para el fin que estamos evaluando.

- ¿Cuál es la influencia del paciente en la obtención del PRP? Es posible que en distintos estudios no se haya llevado a cabo una evaluación del paciente previa a la obtención del producto, y que la función plaquetaria del mismo no sea adecuada o conveniente para la elaboración de un producto final fiable.

- ¿Cómo actúa realmente el PRP cuando lo aplicamos al lecho, es decir, cómo se lleva a cabo exactamente la liberación y activación de factores en el lecho a regenerar, espacial y temporalmente? En algunos estudios no se especifica si el PRP se activa previamente con algún sustrato (cloruro cálcico, trombina bovina, TRAP...) o bien ni siquiera si se activa, y por ello cabe esperar que la liberación y/o activación de los factores en el lecho difiera según si el PRP se activa o no y según el método de activación. Es necesaria mayor investigación estudiando todos y cada uno de los factores que puedan afectar la respuesta del PRP.

Con todo lo observado parece ser que, en definitiva, la aplicación del PRP en la Odontología seguirá decayendo hasta llegar a un punto en que no se considere finalmente válida como opción coadyuvante en la terapéutica rehabilitadora de los defectos óseos, si bien existen muchos campos de la Medicina en los que su aplicación sobre los tejidos blandos por su alto potencial cicatrizante puede ser factible.

\section{SUIMIMARY}

The aim of this work was to make a review about the evolution of the platelet rich plasma (PRP) in literature. After an introduction, the main components of the PRP are showed, giving more relevance to the growing factors to continue with the obtaining procedure and its aplication in the surgical aspect. Later, a review about the regeneration process by means of histological findings is made from the very first moment to the sixth week. In the discussion, it can be observed that there is a great polemic between the found studies about the usefulness of the PRP in osseous regeneration, and then some potencial riks about the utilization of the PRP are put forward to finish with a brief review of comparative studies between different obtaining and activation methods. Finally, some conclusions are established and the bibliography searched is presented.

\section{KEYWORDS}

Platelet rich plasma, regeneration, PRP.

\section{BIBLIOGRAFÍA}

1. Maiorama C, Sommarvina L, Brivio P, Sigurtá D, Santero F. Aumento del seno maxilar con hueso bovino anorgánico (Bio-Oss) y plasma autólogo rico en plaquetas: Estudios clínicos e histológicos preliminares. Revista Internacional de Odontología Restauradora y Conservadora; 2003 7(3): 239-47.

2. Lynch S E. Introduction. Tissue Engeneering: Aplicationns in Maxillofacial Surgery and Periodontics. Editorial: Quintessense Books, 1999 Illinois-Estados Unidos.

3. Camelo M, Nevins M L, Schenk R K, Lynch S E. Regeneración periodontal en bifurcaciones se clase II en seres humanos mediante el uso de factor de crecimiento plaquetario humano recombinante purificado-BB (rhPDGFBB) y aloinjerto óseo. Revista Internacional de Odontología Restauradora y Conservadora. 2003;7(3): 225-37.

4. Anitua E. Un nuevo enfoque en la regeneración ósea. Plasma rico en factores de crecimiento (P.R.G.F). Editorial: Puesta al día publicaciones, S.L. 2000 Vitoria-España.

5. Spector M. Basic priciples of tissue Engeneering. Tissue Engeneering: Aplicationns in Maxillofacial Surgery and Periodontics. Editorial: Quintessense Books.1999, Illinois -Estados Unidos.

6. Gonshor A. Tecnicas para producir plasma rico en plaquetas y concentrado plaquetario: Antecedentes y proceso. Revista Internacional de Odontología Restauradora y Conservadora. 2002; 6 (6):583-93. 
7. Marx R E. Platelet-Rich Plasma: A source of multiple autologous growth factors for bone grafts. Tissue Engeneering: Aplicationns in Maxillofacial Surgery and Periodontics. Editorial: Quintessense Books.1999, Illinois -Estados Unidos.

8. Martínez-González JMª , Cano-Sánchez J, GonzaloLafuente JC, Campo-Trapero J, Esparza-Gómez GC, Seoane-Lestón JM. ¿Existen riesgos al utilizar los concentrados de plasma rico en plaquetas (PRP) de uso ambulatorio? Medicina Oral. 2002; 7(5):375-90.

9. Hollinger J O, Buck D C, Bruder S P. Biology of bone healing: Its Impact on clinical therapy. Tissue Engeneering: Aplicationns in Maxillofacial Surgery and Periodontics. Editorial: Quintessense Books. 1999, Illinois-Estados Unidos.

10. Marx RE, Carlson ER, Eichstaedt RM, Schimmele SR, Strauss JE, Georgeff KR. Platelet rich plasma: Growth factor enhancement for bone grafts. Oral Surg Oral Med Oral Pathol Oral Radiol Endod. 1998;85(6):63846.

11. Anitua E. La utilización de los factores de crecimiento plasmáticos en cirugía oral, maxilofacial y periodoncia (P.R.G.F.). RCOE. 2001;6(3):305-15.

12. Merkx M A W, Fennis JPM, Verhagen CM, Stroenlinga PJW. Reconstruction of the mandible using preshaped $2.3 \mathrm{~mm}$ titanium plates, autogenous particulate corticocancellous bone grafts and platelet rich plasma: a report on eight patients. Int J Oral Maxillofac Surg. 2004;33: 733-9.

13. Marx RE. Platelet rich plasma (PRP): What is $P R P$ and what is not PRP? Implant Dent. 2001;10(4):225-8.

14. Anitua E. Plasma rich in growth factors: preliminary results of use in the preparation of future sites for implants. Int J Oral Maxillofac Implant. 1999; 14(4):52935.

15. Whitman DH, Berry RL, Green DM. Platelet gel: An autologous alternative to fibrin glue with aplications in oral and maxillofacial surgery. J Oral Maxillofacial Surg. 1997;55:1294-1299.

16. Sonnleitner D, Huemer P, Sullivan DY. A simplified technique for producing platelet rich plasma and platelet concentrate for intraoral bone grafting techniques: A clinical note. Int J Oral Maxillofac Implant. 2000;15(6):879-82.
17. Lozada JL, Caplanis N, Proussaefs P, Willardsen J, Kammeyer G. Platelet-rich plasma application in sinus graft surgery: Part I-Background and processing techniques. J Oral Implantol 2001;27:38-42.

18. Efeoglu C, Akçay YD, Ertürk S. A modified method for preparing platelet rich plasma: An experimental study. J Oral Maxillofacial Surg.2004;62:1403-7.

19. Garg A. Grafting materials in repair an restoration. Tissue Engeneering: Aplicationns in Maxillofacial Surgery and Periodontics. Editorial: Quintessense Books, 1999 Illinois - Estados Unidos.

20. Marx RE. Platelet rich plasma: Evidence to support its use. J Oral Maxillofac Surg. 2004; 62: 489-96.

21. Tayapongsak P, O'Brien DA, Monteiro CB, Arceo-Diaz LY. Autologous fibrin adhesive in mandibular reconstruction with particulate cancellous bone and marrow. J Oral Maxillofacial Surg. 1994;52:161-6.

22. De Obarrio JJ, Aráuz-Dutari J I, Chamberlain TM, Croston A. Uso de factores de crecimiento autólogos en cirugía periodontal: Biotecnología de gel de plaquetas: Informe de casos. Revista Internacional de Odontología Restauradora y Conservadora; 2000 4(5): 511-21.

23. Rodríguez A, Anastassov GE, Lee H, Buchbinder D, Wettan H. Maxillary sinus augmentation with deproteinated bovine bone and platelet rich plasma with simultaneous insertion of endosseous implants. Int J Oral Maxillofac Surg. 2003; 61: 157-63.

24. Oyama T, Nishimoto S, Tsugawa T, Shimizu F. Efficacy of Platelet -rich plasma in alveolar bone grafting. J Oral Maxillofacial Surg 2004;62:555-8.

25. Howell HT, Fiorellini JP, Paquette DW, Offenbacher S, Giannobile W, Lynch SE. A fase I / II clinical trial to evaluate a combination of recombinant human plateletderived growth factor-BB and recombinant human insuline-like growth factor-I in patients with periodontal disease. J Periodontol. 1997;68(12):1186-93.

26. Butterfield KJ, Bennet J, Gronowicz g, Adams D. Effect of platelet rich plasma with autogenous bone graft for sinus augmentation in a rabbit model. J Oral Maxillof Surg. 2005;63:370-6.

27. Froum S J, Wallace SS, Tarnow D P, Cho SC. Efecto del plasma rico en plaquetas sobre el crecimieto óseo y la osteointegracion en injertos de seno maxilar en seres 
humanos: tres informes de casos bilaterales. Revista Internacional de Odontología Restauradora y Conservadora. $2002 ; 6(1): 45-53$.

28. Shanaman R, Filstein MR, Danesh-Meyer MJ. Aumento localizado de la cresta utilizando ROG y plasma rico en plaquetas: Casos clínicos. Revista Internacional de Odontología Restauradora y Conservadora. 2001; 5(4):53-363.

29. Birgit Wenz. Characteristics of Bio-Oss and Bio-Guide. Advanced Techniques for Bone Regeneration with BioOss and Bio-Guide. Editorial: RCl Libri, 2003 MilanoItalia.

30. Aghaloo TL, Moy PK, Freymiller EG. Investigation of platelet-rich plasma in rabbit cranial defects: A pilot study. J Oral Maxillof Surg. 2002;60:1176-81.

31. Kassolis JD, Rosen PS, Reynolds MA. Alveolar ridge aumentation utilizing platelet-rich plasma in combination with freeze-dried bone allograft: Case series. J Periodontol. 2000;71(10):1654-61.

32. Freymiller EG, Aghaloo TL. Platelet rich plasma: Ready or not? J Oral Maxillofac Surg. 2004;62:484-8.

33. Olea - Rosson J, Olea-Rosson N. Elevación del piso nasal y factores de crecimiento de plaquetas con implantes oseointegrados y estudio de microscopía óptica y electrónica. Rev Esp Odontoestomatológica de implantes. 2003; $11(4): 226-33$.

34. B-H Choi, S-J Zhu, B-Y Kim, J-Y Huh, S-H Lee, J-H Jung. Effect of platelet-rich plasma (PRP) concentration on the viability and proliferation of alveolar bone cells: an in vitro study. Int J Oral Maxillofac. Surg 2005;34:420-4.

35. Philippart P, Daubie V, Pochet R. Sinus graftingusing recombinant human tissue factor, platelet-rich plasma gel, autologous bone, and anorganic bovine bone mineral xenograft: histologic analysis and case reports. The Int Journ of Oral and Maxilofacial Implants. 2005;20(2): 274-81.

36. Wiltfang J, Kloss F.R, Kessler P, Nkenke E, SchultzeMosgau S, Zimmermann R, Schlegel K.A. Effects of platelet-rich plasma on bone healing in combination with autogenous bone and bone substitutes in criticalsize defects. An animal experiment.Clin Oral Impl. Res 2004;15:187-93.

37. Arpornmaeklong P, Kochel M, Depprich R, Kübler NR, Würzler KK. Influence of platelet-rich plasma (PRP) on osteogenic differentation of rat bone marrow stromal cells. An in vitro study. Int. J. Oral Maxillofac Surg 2004; 33:60-70.

38. Landesberg R, Burke A, Pinsky D, Katz R, Vo J, Eisig SB, $\mathrm{Lu} \mathrm{HH}$. Activation of platelet-rich plasma using thrombin receptor agonist peptide. J Oral Maxillofac Surg 2005;63:529-35.

39. Weibrich G, Kleis W.K.G, Hitzler W.E, Hafner G. Comparison of the platelet concentrate collection system with the plasma-rich-in-growth-factors kit to produce platelet-rich plasma: a technical report. The Int Journ of Oral and Maxilofacial Implants 2005;20(1): 118-23.

40. Weibrich G, Kleis WKG, Hitzler W.E, Hafner G. Growth Factor Levels in the platelet-rich plasma produced by 2 different methods: curasan-type PRP kit versus PCCS PRP system. The Int Journ of Oral and Maxilofacial Implants 2002;17(2):184-90.

41. Tsay RC, Vo J, Burke A, Eisig SB, Lu HH, Landesberg R. Differential grow factor retention by platelet-rich plasma composites. J Oral Maxillofac Surg. 2005;63: 521-8.

42. Okuda K, Tai H, Tanabe K, Suzuki H, Sato T, Kawase T, SaitoY, Wolff LF, Yoshie H. Platelet rich plasma combined with a porous hydroxyapatite graft for the treatment of intrabony periodontal defects in humans: a comparative controlled clinical study. J Periodontol. 2005;76: 890-8.

43. Kanno T, Takahashi T, Tsujisawa T, Ariyoshi W, Nishihara T. Platelet-rich plasma enhances human osteoblasts-like cell proliferation and differentiation. J Oral Maxillofac Surg. 2005;63:362-9.

44. Okuda K, Kawase T, Momose M, Murata M, SaitoY, Suzuki H,Wolff L.F, Yoshie H. Platelet-rich plasma contains high levels of platelet-derived growth factor and transforming growth factor-B and modulates the proliferation of periodontally related cells in vitro. J Periodontol. 2003; 74:849-57.

45. Swennen GRJ, Schutyser F, Mueller MC, Kramer FJ, Eulzer C, Schliephake H. Effect of platelet-rich-plasma on cranial distraction osteogenesis in sheep: preliminary clinical and radiographic results. Int J Oral Maxillofac Surg. 2005;34:294-304.

46. Philippart P, Brasseur M, Hoyaux D, Pochet R. Human recombinant tissue factor, platelet-rich plasma,and 


\section{AVANCES}

Volumen 19 - $\mathrm{N}^{\circ} 1$ - Abril 2007

tetracycline induce a high-quality human bone graft: a 5-year survey. Int J Oral Maxillofac Implants. 2003;18: 411-6.

47. Wojtowicz A, Chaberek S, Kyrst L, Urbanowska E, Ciechowicz K, Ostrowski K. Fourier and fractal analysis of maxillary alveolar ridge repair using platelet rich plasma (PRP) and inorganic bovine bone. Int J Oral Maxillofac Surg. 2003;32:84-6.
48. Dugrillon A, Eichler H, Kern S, Küter H. Autologous concentrated platelet-rich plasma (cPRP) for local application in bone regeneration. Int. J. Oral Maxillofac. Surg. 2001;31:615-9.

49. Jakse N, Tangl S, Gilli R, Berghold A, Lorenzoni M, Eskici A, Haas R, Pertl C. Influence of PRP on autogenous sinus grafts.An experimental study on sheep. Clin. Oral Impl. Res 2003; 14:578-83. 